\title{
TIPOLOGIA DA FISSURAÇÃO EM EDIFICAÇÃO DA ARQUITETURA LUSO- MARANHENSE: ESTUDO DE CASO
}

\author{
OLIVEIRA, A. H. S. 1 \\ Engenheiro Civil \\ Tac Construções Eireli \\ Maranhão; Brasil \\ antoniohelson@hotmail.com
}

\author{
ARAÚJO, M. V. ${ }^{3}$ \\ Mestranda \\ Universidade Federal do Pará \\ Pará; Brasil \\ myrelav.araujo@gmail.com
}

\author{
AGUIAR, E. A. B. ${ }^{2}$ \\ Professor Doutor \\ Universidade Estadual do Maranhão \\ Maranhão; Brasil \\ eduardoaguiar.eng@live.com
}

\author{
ARAÚJO NETTO, R. N. R. ${ }^{4}$ \\ Engenheiro Civil \\ Prefeitura Municipal de Tasso Fragoso \\ Maranhão; Brasil \\ raimundon.araujo@gmail.com
}

\section{RESUMO}

O estudo visa a identificação dos tipos de fissuras em alvenarias e estruturas de concreto de um edifício localizado no Centro Histórico de São Luís no Estado do Maranhão, com o objetivo de definir as causas e tratamentos das fissuras. Além disso, foi realizado o ensaio de carbonatação no concreto. Mediante os resultados, observou-se que as causas das fissuras em alvenarias mistas foram devido ao apodrecimento e desgaste da estrutura de madeira presente no seu interior e desagregação da argamassa de revestimento. Após o diagnóstico nas estruturas de concreto, observamos que o reboco foi feito com uma camada porosa que trabalha suportando a umidade local na qual tem contribuição direta para o fenômeno da carbonatação no concreto que levou a estrutura ao processo de ruína. Nesse sentido, os tratamentos que podem ser realizados para a alvenaria são a manutenção preventiva da madeira e para o concreto, a recomposição da camada carbonatada e reforço estrutural.

Palavras-chave: fissuras, alvenarias, estruturas de concreto.

\section{ABSTRACT}

The study aims to identify the types of cracks in masonry and concrete structures of a building located in the São Luís Historic Center in the state of Maranhão, with the objective of defining the causes and treatments of cracks. In addition, the carbonation test on the concrete was performed. From the results, it was observed that the causes of cracks in mixed masonry were due to the rot and wear of the wood structure present inside and the disintegration of the coating grout. After the diagnosis in the concrete structures, it was observed that the plaster was made with a porous layer that works supporting the local humidity in which it has a direct contribution to the phenomenon of carbonation in the concrete that led the structure to the ruin process. In this sense, the treatments that can be performed for masonry are the preventive maintenance of wood and concrete, the recomposition of the carbonated layer and structural reinforcement.

Keywords: cracks, masonry, concrete structures.

\section{INTRODUÇÃO}

As fissuras são um tipo de patologia comum nas edificações e influenciam nas características estruturais da obra como durabilidade e estética. Elas são geradas nas alvenarias e estruturas de concreto devido a atuação de tensões nos materiais. Quando a solicitação é maior do que a capacidade de resistência do material, a fissura tem a tendência de aliviar suas tensões (CORSINI, 2010). A fissuração em alvenaria histórica não reforçada pode ser causada por assentamentos diferenciais, fluência, fadiga, vibrações, terremotos, tensões induzidas por temperatura e carga (VERSTRYNGE et al., 2018). Segundo Holanda Jr. (2008), as fissuras são as causas mais constantes de falha de desempenho em alvenarias, pois os materiais empregados na sua fabricação, por exemplo, cerâmicas, argamassa e concreto, são frágeis. Dependendo da causa e gravidade do dano, a quebra de alvenaria pode levar à perda de coesão em paredes de suporte de carga, redução da capacidade estrutural e até colapso em caso de instabilidade do crescimento das trincas (VERSTRYNGE et al., 2016). Nessa perspectiva, é importante fazer mapeamento e o monitoramento das fissuras com o objetivo de avaliar os danos, uma vez que os padrões de fissuras fornecem informações vitais sobre a causa e a gravidade do dano (BINDA et al., 2009). Em estruturas de concreto armado, a deterioração tem sido motivo de grande preocupação nas últimas décadas, à 
medida que a edificação está envelhecendo, pode deteriorar rapidamente e o que acaba tornando cada vez mais vulnerável a falhas (CUI et al., 2017). Uma das principais causas de deterioração das estruturas de concreto é a corrosão do reforço (CAIRNS et al., 2005; VAL et al., 2009; APOSTOLOPOULOS et al., 2013). Na primeira fase ocorre o início da corrosão pelo acesso de íons cloreto ou de ambiente carregado de dióxido carbono $\left(\mathrm{CO}_{2}\right)$, a segunda e terceira fase são caracterizadas pelo início das fissuras e sua propagação no concreto, respectivamente. Entre as três fases, a primeira normalmente leva o tempo mais longo, a segunda define o fim da vida útil funcional em que o reparo ou a substituição é necessária para estruturas de concreto armado corroídas, a terceira etapa é o estágio mais curto entre os três (CUI et al., 2017). Através de experiências práticas e observações experimentais (ANDRADE et al., 1993; LI, 2005; OTSUKI et al., 2000), apontam que estruturas de concreto armado se deterioram aceleradamente em termos de manutenção, como rachaduras, em comparação a segurança, por exemplo, resistência. Sendo assim, é importante realizar averiguação do processo de fissuração e a sua abertura no concreto, visto que esse parâmetro é relevante para avaliação de estruturas de concreto armado. Å vista disso, a presente pesquisa visa o estudo das fissuras em alvenarias de pedra argamassada e estruturas de concreto em um edifício de arquitetura luso-maranhense. Apresentaremos as origens, causas e as técnicas mais recomendadas de recuperação desse problema.

\section{METODOLOGIA}

\subsection{Caracterização da edificação}

A área de estudo é um sobrado da arquitetura luso-maranhense (figura 1), constituindo-se em um edifício antigo do Centro Histórico de São Luís - MA. Caracterizado como sobrado tradicional, sob jurisprudência Federal, faz apologia ao estilo português. A área do lote possui $382 \mathrm{~m}^{2}$, a área do terreno edificada dispõe $618 \mathrm{~m}^{2}$ e a área livre apresenta $72,13 \mathrm{~m}^{2}$. A edificação apresenta estrutura mista de alvenaria de pedra e madeira. Os componentes mais novos observados no casarão possuem estrutura de concreto.

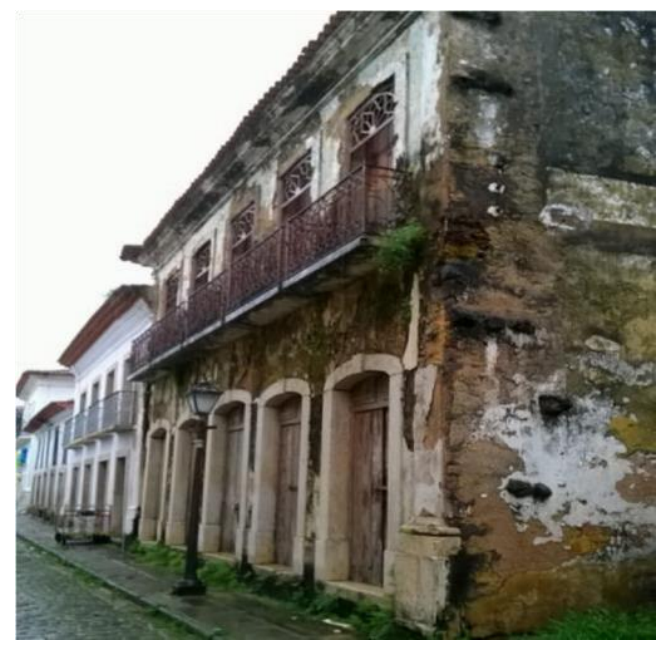

Figura 1: Área de estudo: fachada do sobrado 559

\subsection{Alvenaria de pedra argamassada}

Foram encontradas estruturas feitas com pedras e revestidas com argamassa de cal, areia e barro. Nesse tipo de estrutura foram analisadas as causas que provocaram o conjunto de fissuras existentes ao longo dos anos de vida útil da edificação. O levantamento das fissuras foi realizado com auxílio de um paquímetro, que permite medir o tamanho da abertura da fissura na alvenaria. Depois dessa etapa, os tipos de fissuras foram classificados, conforme a Norma de Impermeabilização (NBR 9575:2010), descrita na Tabela 1. Sabendo da existência de todos os tipos de fissuras, em seguida, foi quebrado a superfície dessas alvenarias para compreender as causas dos problemas, bem como a busca da solução adequada para cada tipo de situação. Observou-se a existência da madeira junto a alvenaria de pedra argamassada (figura 2) no Sobrado em estudo, pois a madeira confere confinamento e resistência à flexão a parede. 


\section{СВРАT 2020

Tabela 1 - Tipos de fissuras de acordo com a sua abertura

\begin{tabular}{|c|c|c|}
\hline MICROFISSURA & menor que $0,05 \mathrm{~mm}$ & \multirow{4}{*}{$\begin{array}{c}\text { Segundo NBR 9575: } 2010 \text { (Norma } \\
\text { de Impermeabilização) }\end{array}$} \\
\hline FISSURA & até $0,5 \mathrm{~mm}$ & \\
\hline TRINCA & maior que $0,5 \mathrm{~mm}$ e menor que $1 \mathrm{~mm}$ & \\
\hline RACHADURA & maior que $1 \mathrm{~mm}$ & \\
\hline
\end{tabular}

Fonte: NBR 9575: 2003

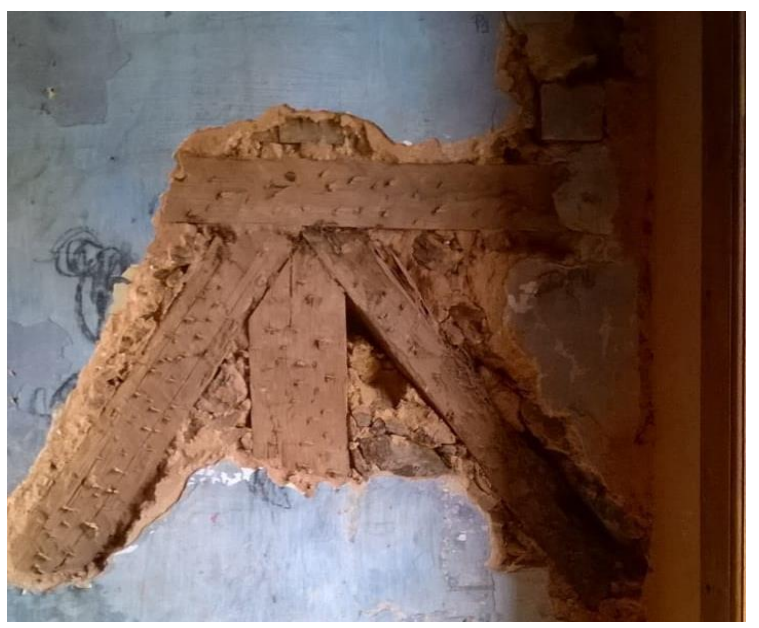

Figura 2: Alvenaria de pedra argamassada com madeira

\subsection{Estruturas de concreto}

No casarão foi observado a existência de pilares e vigas, estruturas bem recentes na edificação. Em um dos pilares analisados, verificou-se a existência de armaduras parcialmente expostas (figura 3). À vista disso, foi inicialmente executado o levantamento das fissuras com auxílio de um paquímetro e classificadas conforme a NBR 9575:2010 em um pilar e uma viga. Em seguida, fez-se o ensaio não destrutivo com base na esclerometria com o intuito de avaliar a dureza superficial do concreto, segundo a NBR 7584:2012. Por fim, analisamos a interferência da carbonatação em três pilares e uma viga com a aplicação de fenolftaleína, um produto químico que permite verificar a área que sofreu carbonatação. Após a aplicação, a área que resultou em uma coloração violeta, determinou a região sem carbonatação, enquanto os que permaneceram incolor, determinou a região carbonatada.

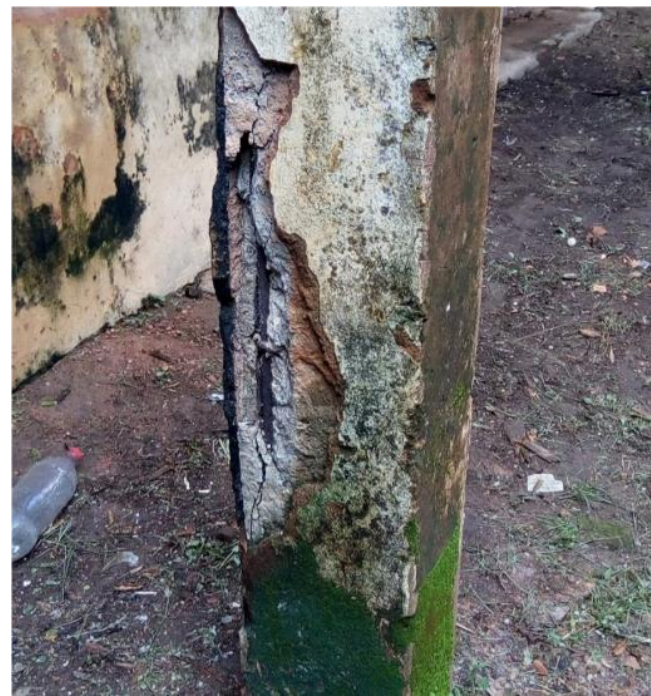

Figura 3: Pilar de concreto com armadura parcialmente exposta 


\section{RESULTADOS E DISCUSSÕES}

\subsection{Origem e análise dos problemas na alvenaria e estruturas de concreto}

\subsubsection{Alvenaria de pedra argamassada}

Em alvenaria de pedra argamassada com madeira observamos que as causas são por conta do apodrecimento e degradação da madeira. Adiante, na figura 4 tem-se uma ilustração do fato supracitado.
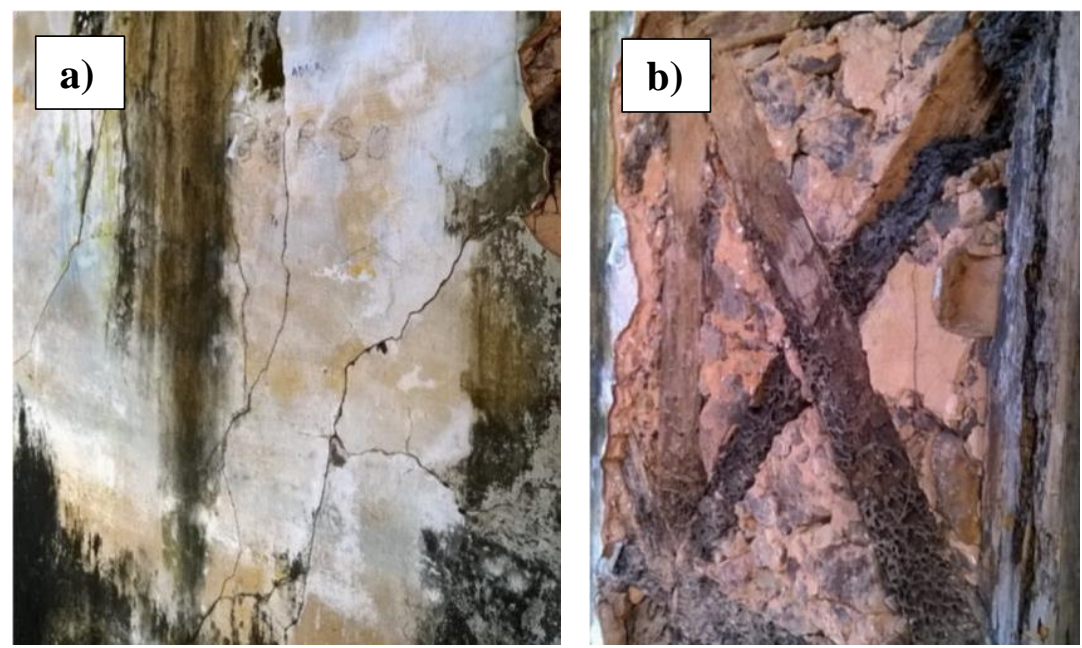

Figura 4: Parede de alvenaria de pedra argamassada com madeira. (a) Fissuras e trincas, (b) Apodrecimento da madeira

Nota-se na figura 4 que as peças de madeiras usadas na construção de alvenarias tinham um travamento entre si e a disposição nelas mesmas em diagonal formam diversos triângulos que foram preenchidos por pedra com cal e areia. A madeira que antes dava o travamento na diagonal primária e secundária da parede, tornou-se removível, provocando problemas patológicos nas alvenarias. No levantamento das aberturas nas alvenarias foram localizadas fissuras, trincas e rachaduras com $0,5 \mathrm{~mm}, 0,8 \mathrm{~mm}$ e $2 \mathrm{~mm}$ (figura $5 \mathrm{a}, 5 \mathrm{~b}, 5 \mathrm{c}$ ), respectivamente. Além disso, foram detectados organismos xilófagos nas peças de madeira, responsáveis por danificá-las.
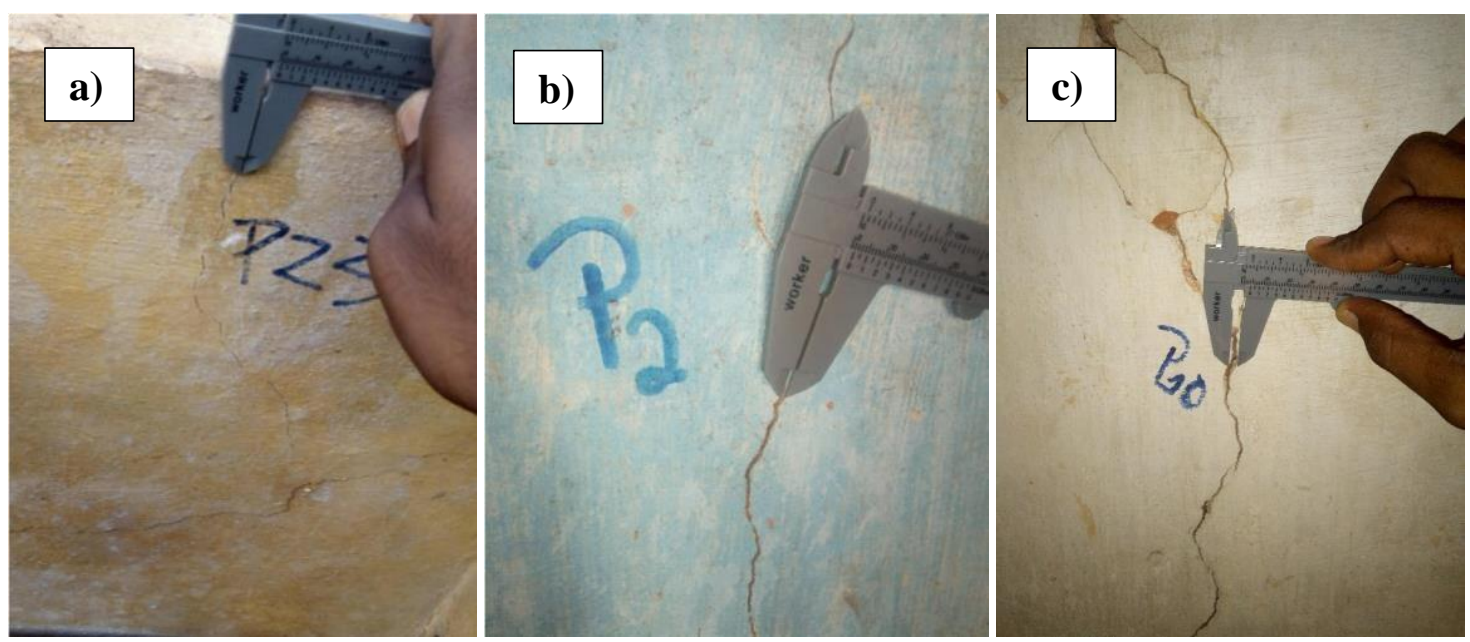

Figura 5: Levantamento das aberturas nas alvenarias. (a) Fissura com 0,5 mm, (b) Trinca com $0,8 \mathrm{~mm}$, (c) Rachadura com $2 \mathrm{~mm}$ 


\subsubsection{Estruturas de concreto}

No levantamento das aberturas em viga e pilar, localizou-se rachadura de $2 \mathrm{~mm}$ (figura 6a) e trinca de $0,9 \mathrm{~mm}$ (figura $6 \mathrm{~b}$ ), respectivamente. Após a identificação das aberturas no concreto, foi executado o ensaio esclerométrico em três pilares e uma viga para verificar sua dureza superficial. A tabela 2 apresenta os resultados do ensaio com intervalo de 9 a 16 leituras do índice esclerométrico em cada peça de concreto. Em seguida, foi calculado o índice esclerométrico efetivo médio para cada estrutura e através desse valor encontrado, inserimos na tabela de esclerometria presente em norma, determinando a resistência da peça ensaiada.
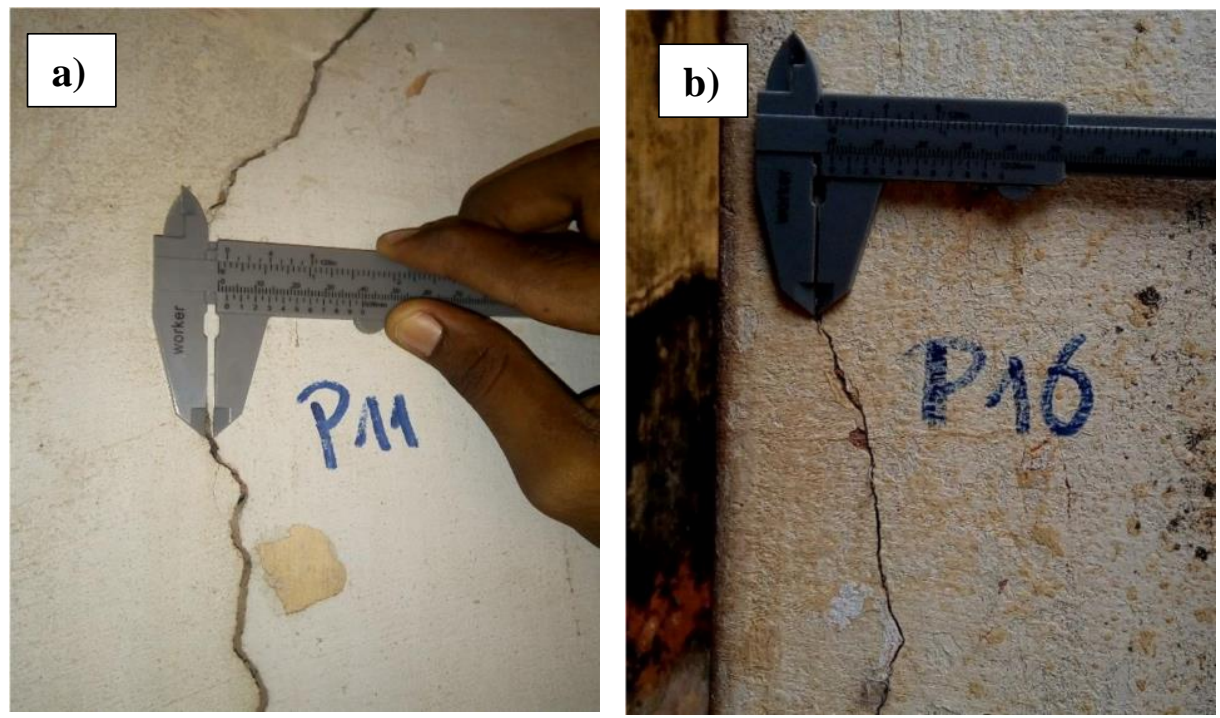

Figura 6:Levantamento das aberturas. (a) Rachadura em viga com $2 \mathrm{~mm}$ (b) Trinca em pilar com $0,9 \mathrm{~mm}$

Tabela 2 - Valores esclerométricos individuais para cada peça estrutural

\begin{tabular}{|c|c|c|}
\hline \multicolumn{2}{|c|}{ PILAR 1 } \\
\hline PONTO & ÍNDICE ESCLEROMÉTRICO \\
\hline 1 & 42 \\
\hline 2 & 43 \\
\hline 3 & 48 \\
\hline 4 & 45 \\
\hline 5 & 43 \\
\hline 6 & 38 \\
\hline 7 & 32 \\
\hline 8 & 45 \\
\hline 9 & 33 \\
\hline 10 & 38 \\
\hline 11 & 37 \\
\hline 12 & 48 \\
\hline 13 & 45 \\
\hline 14 & 38 \\
\hline 15 & 40 \\
\hline
\end{tabular}




\begin{tabular}{|c|c|c|}
\hline \multicolumn{3}{|c|}{$\begin{array}{rr}\text { PILAR } 2 \\
\end{array}$} \\
\hline PONTO & ÍNDICE ESCLEROMÉTRICO & RESISTÊNCIA (MPa) \\
\hline 1 & 29 & \multirow{9}{*}{25,62} \\
\hline 2 & 32 & \\
\hline 3 & 32 & \\
\hline 4 & 36 & \\
\hline 5 & 30 & \\
\hline 6 & 36 & \\
\hline 7 & 26 & \\
\hline 8 & 36 & \\
\hline 9 & 38 & \\
\hline \multicolumn{3}{|c|}{ PILAR 3} \\
\hline PONTO & ÍNDICE ESCLEROMÉTRICO & RESISTÊNCIA (MPa) \\
\hline 1 & 21 & \multirow{9}{*}{8,85} \\
\hline 2 & 18 & \\
\hline 3 & 17 & \\
\hline 4 & 18 & \\
\hline 5 & 20 & \\
\hline 6 & 26 & \\
\hline 7 & 20 & \\
\hline 8 & 26 & \\
\hline 9 & 20 & \\
\hline \multicolumn{3}{|c|}{ VIGA } \\
\hline PONTO & ÍNDICE ESCLEROMÉTRICO & RESISTÊNCIA (MPa) \\
\hline 1 & 24 & \multirow{9}{*}{15,04} \\
\hline 2 & 28 & \\
\hline 3 & 26 & \\
\hline 4 & 25 & \\
\hline 5 & 24 & \\
\hline 6 & 27 & \\
\hline 7 & 25 & \\
\hline 8 & 28 & \\
\hline 9 & 25 & \\
\hline
\end{tabular}

Para verificação do fenômeno da carbonatação utilizamos a fenolftaleína, um produto químico que permite verificar a área que sofreu carbonatação devido a presença do dióxido de carbono presente no ar que circula em volta dos pilares e da viga penetrando os poros do concreto, conforme apresenta a figura 7 e 8 . Após a aplicação da fenolftaleína, a área com a coloração violeta determinamos o local sem carbonatação, enquanto os que permaneceram incolor, determinamos a área carbonatada. 


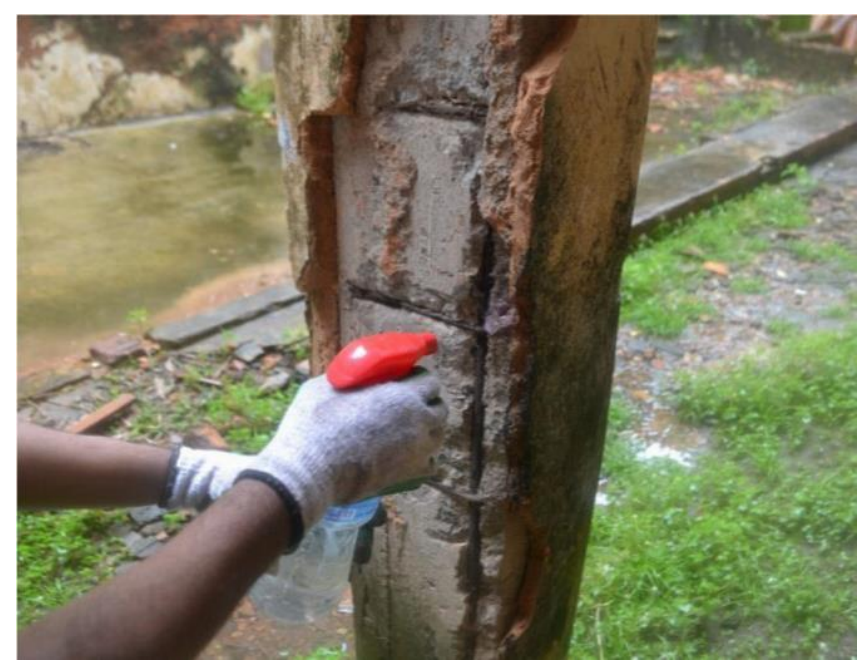

Figura 7: Aplicação de fenolftaleína no pilar de concreto

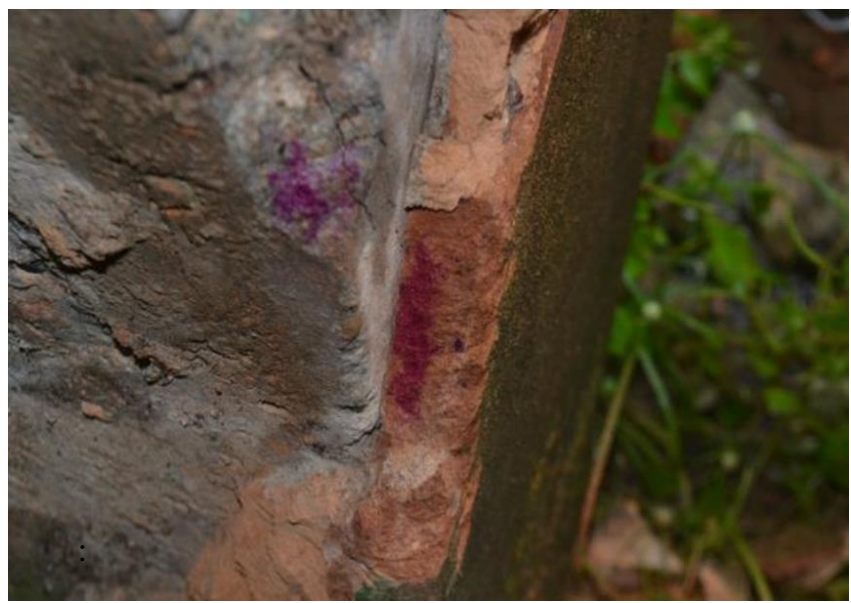

Figura 8: Área não carbonatada identificada com a coloração violeta

Identificado os defeitos no concreto verificamos que o reboco foi feito de uma camada porosa, que trabalha suportando a umidade do local. No entanto, esta umidade não causa problema na argamassa tradicional de alvenaria. No caso do concreto da edificação em estudo em que a argamassa de barro funciona como recobrimento, isto é, proteção da armadura, observamos que a sua utilização foi um fator contribuidor para que ocorresse a carbonatação. O diagnóstico dos pilares e da viga levou à conclusão de que a causa principal da fissuração foi o fenômeno da corrosão reconhecida através da abertura dos pilares, das vigas devido à presença constante do ambiente carregado de dióxido de carbono. A partir disso constatamos, portanto, que os pilares se encontravam com a durabilidade visivelmente comprometida. No caso da viga que possuía um vão de 12 metros de comprimento, verificamos que a mesma estava carbonatada e precisava de intervenção urgente, pois enfrentava um processo de degradação, o qual poderia culminar no seu arruinamento. Além disso, através da análise dos resultados do ensaio esclerométrico, a peça que mais se encontrava comprometida foi o pilar 3 devido a sua resistência ser a menor.

\subsection{Tratamentos}

\subsubsection{Alvenaria de pedra argamassada}

Como foi detectado o ataque de organismos xilófagos nas peças de madeiras, é preciso recorrer ao tratamento com carácter curativo que consiste na injeção e pulverização de produtos químicos orgânicos na madeira com o intuito de eliminar os agentes degradadores e impedir que ocorra a continuação do ataque a madeira. No caso das alvenarias de pedra com madeira, vale salientar que é necessário demolir superficialmente a alvenaria para poder aplicar o produto protetor de agentes degradadores. Para a madeira em estado seco, o produto químico que deve ser utilizado é o Glicol-borato, pois o borato penetra na madeira seca, eliminando a atividade de qualquer fungo. A penetração deste preservativo é limitada e a função mais relevante é prevenir fungos não identificados e evitar que aconteça o seu crescimento. Para a madeira em 
estado aquoso, o produto químico protetor é o Cromo Cobre Arsênio (CCA). O cobre funciona como primeiro fungicida, o arsênio o segundo fungicida e inseticida, bem como o cromo que tem funcionalidade de fixador que provê os raios ultravioleta. Para pequenas fissuras na alvenaria, a solução preventiva é retocar o reboco com material novo, usando argamassa ou massa acrílica e fazer a manutenção periódica desse reboco, visto que, com o passar do tempo as fissuras podem reaparecer. Em caso de trinca existe a necessidade de quebra superficial da parede, para verificação do que está levando a ocorrência da anomalia. Observado o defeito, pode-se aplicar massa acrílica, selador acrílico ou também um gradil de poliéster e argamassa. Para a rachadura, sugerimos a solução preventiva nesta situação seria demolir a parede até um ponto de se colocar uma cortina de ferro em diagonal e cobrir com argamassa.

\subsubsection{Estruturas de concreto}

Para a viga de concreto que se encontrava carbonatada, faz-se necessário construir uma nova viga de concreto protendido que venha suportar o vão de 12 metros. Para os pilares de concreto, pelo fato de todos estarem comprometidos pelo o fenômeno da carbonatação e corrosão, a solução seria construir uma camisa metálica, que posteriormente seria concretada na posição dos pilares existentes sem demoli-los. Para isso, a camisa metálica teria uma seção maior em relação a seção existente. Após a construção das camisas em cada pilar, a estrutura existente ficaria dentro do novo sem nenhuma função estrutural.

\section{CONCLUSÃO}

Com base nas análises dos resultados, a causa maior da fissuração em alvenaria de pedra/madeira foi o envelhecimento e apodrecimento da madeira devido sua idade, bem como aos agentes degradadores que se alimentam da madeira. Com isso, observamos o comprometimento das alvenarias sendo avistado por meio de fissuras, trincas e rachaduras decorrentes da movimentação da madeira, já nas estruturas de concreto, identificamos que o fator gerador de fissuras, trincas e rachaduras foi o fenômeno da corrosão, problema este que reduz a durabilidade do concreto.

\section{REFERÊNCIAS}

APOSTOLOPOULOS, Charis A.; DEMIS, Sotiris; PAPADAKIS, Vagelis G. Chloride-induced corrosion of steel reinforcement-Mechanical performance and pit depth analysis. Construction and Building Materials, v. 38, p. 139$146,2013$.

ASSOCIAÇÃO BRASILEIRA DE NORMAS TÉCNICAS. NBR 7584: Concreto endurecido - Avaliação da dureza superficial pelo esclerômetro de reflexão - Método de ensaio. Rio de Janeiro. 2012.

NBR 9575: Projeto de Impermeabilização - Seleção e projeto. Rio de Janeiro. 2010.

BINDA, Luigia; SAISI, Antonella. Application of NDTs to the diagnosis of Historic Structures. In: 7th International Symposium on Nondestructive Testing in Civil Engineering. 2009.

CAIRNS, John et al. Mechanical properties of corrosion-damaged reinforcement. ACI Materials Journal, v. 102, n. 4, p. 256, 2005.

CORSINI, R.. Revista Téchne. ed. 160 São Paulo: Pini, 2010.

CUI, Zhen; ALIPOUR, Alice. Concrete cover cracking and service life prediction of reinforced concrete structures in corrosive environments. Construction and Building Materials, v. 159, p. 652-671, 2018.

HOLANDA Jr., O.G. Influência de recalques em edifícios de alvenaria estrutural. 2002. 242f. Tese (Doutorado em Engenharia Civil) - Escola de Engenharia de São Carlos. Universidade de São Paulo, São Carlos, 2008.

LI, Chun Qing. Time dependent reliability analysis of the serviceability of corrosion affected concrete structures. International Journal of Materials \& Structural Reliability, v. 3, n. 2, p. 105-116, 2005.

MOLINA, F. J.; ALONSO, C.; ANDRADE, C. Cover cracking as a function of rebar corrosion: Part 2-Numerical model. Materials and structures, v. 26, n. 9, p. 532-548, 1993. 


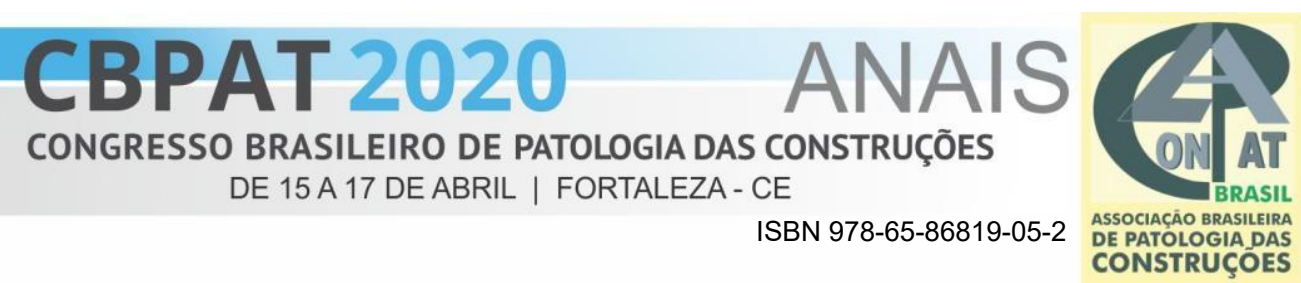

OTSUKI, Nobuaki et al. Influences of bending crack and water-cement ratio on chloride-induced corrosion of main reinforcing bars and stirrups. Materials Journal, v. 97, n. 4, p. 454-464, 2000.

VAL, Dimitri V.; CHERNIN, Leonid. Serviceability reliability of reinforced concrete beams with corroded reinforcement. Journal of structural engineering, v. 135, n. 8, p. 896-905, 2009.

VERSTRYNGE, E.; VAN GEMERT, D. Multi-scale approaches for the assessment of time-dependent mechanical damage in masonry. In: Structural Analysis of Historical Constructions: Anamnesis, Diagnosis, Therapy, Controls: Proceedings of the 10th International Conference on Structural Analysis of Historical Constructions (SAHC, Leuven, Belgium, 13-15 September 2016). CRC Press, 2016. p. 54.

VERSTRYNGE, Els et al. Crack monitoring in historical masonry with distributed strain and acoustic emission sensing techniques. Construction and Building Materials, v. 162, p. 898-907, 2018. 